\title{
Policy climates and climate policies: Analysing the politics of building urban climate change resilience
}

Aditya V. Bahadur, A.V. and Tanner, T.

Accepted 20 August 2013

Pre-print version for Urban Climate

DOI: $10.1016 /$ j.uclim.2013.08.004

\section{Cite as:}

Bahadur, A.V. and Tanner, T.M. (2014) Policy Climates and Climate Policies: Analysing the Politics of Building Urban Climate Change Resilience, Urban Climate 7 (2014) 20-32.

\begin{abstract}
This paper examines the process of building resilience to climate change in urban areas by scrutinising the manner in which initiatives to build resilience interact with the urban policy environments in which they unfold. The urban policy environment is broken into three analytical areas of actors, spaces and discourses. This illustrates the influence of actor networks, epistemic communities and policy entrepreneurs in helping climate change resilience gain traction in urban settings, how discourses attached to Resilience urban resilience are dissonant with those prevailing in ossified Discourses urban policy environments, and the dynamic interaction of interest, agendas and power in decision making that accompanies resilience building processes. The paper applies this framework to case studies of two Indian cities within a major international urban climate change resilience initiative. Using data gathered through a variety of rigorous qualitative research methods, the paper provides insights into the politics of policy processes around urban climate change initiatives. Findings from this study can inform urban development policies and allow resilience project planners to calibrate their efforts to better suit urban policy environments. The paper highlights how issues of politics and power are more significant determinants of such policy processes than conventional, science-led analyses would suggest.
\end{abstract}




\section{Introduction}

The majority of the world's population now lives in cities and developing countries in particular are urbanising rapidly (Dodman and Satterthwaite, 2008; Wilbanks, 2007; Satterthwaite et al., 2007). The location of major urban centres along rivers and coastlines creates exposure to a range of hazards, while low levels of assets and limited access to services and rights reduce the capacity to adapt for many citizens. Despite growing efforts, there remain major gaps in understanding what is needed to build resilience to climate change impacts in urban areas of developing countries (EU, 2012; Gasper et al., 2011; McIntosh et al., 2008; Satterthwaite et al., 2007).

This paper explores the manner in which 'resilience thinking' interacts with urban policy making environments in developing countries such as India. As such, it analyses the way in which different elements of a policy making environment influence initiatives to build the climate change resilience of vulnerable urban populations. It also examines the opportunities and challenges that resilience thinking poses to urban policy environments. Finally, the paper outlines broad themes and issues for those working on urban climate change resilience initiatives to consider in order to reduce the impacts of climate change on vulnerable urban dwellers.

\section{Research setting and case study}

The case study research presented here is located in urban India. $28 \%$ of the Indian population lives in urban areas, the country is fast urbanising as the urban-rural ratio has steadily increased over the last 10 decades (Datta, 2006). At the same time, livelihoods and economic development in the country are highly sensitive to variations in the climate (Jha, 2011). As climate change in India is expected to '...increase the frequency and intensity of current hazards, increase the number of extreme events and spur the emergence of new hazards,' UNEP has put India on a list of 27 countries that are most vulnerable to climate change (Satterthwaite et al., 2007; p. 34, Jha, 2011).

The data for this paper have been collected from Gorakhpur and Indore, cities in the north and centre of India respectively. Gorakhpur has a population of 0.6 million, a decadal population growth rate of $23.61 \%$ (1991-2001), and a high population density of $4559 \mathrm{~km} 2$ (GEAG, 2009). Gorakhpur is already suffering the consequences of climate-related impacts as it,

'...currently faces severe water logging problems, lack of solid waste management and adequate sewerage network (which is prone to clogging and leakages). These problems are exacerbated by current climate hazards, such as heavy rains and flooding, and will worsen as climate change leads to greater precipitation variability (Rockefeller Foundation, 2010, p. 6).'

Indore has a population of 2.4 million and is growing at $4 \%$ annually, a rate substantially higher than the national average (TARU, 2010). Indore is also experiencing climate-related shocks and stresses, as,

'...rising temperatures and increasing incidence of non-monsoon season drought for this landlocked industrial city are contributing to the cities vulnerability and increasing disease 
load. Water scarcity and mining of groundwater will also increase with greater demand and variability in precipitation and droughts. (Rockefeller Foundation, 2010, p. 6).'

The research case study is based on the Asian Cities Climate Change Resilience Network (ACCCRN). Funded by the Rockefeller Foundation, its goal is 'to measurably enhance the resilience of ACCCRN cities' institutions, systems and structures to current and future climate risks, and through this, measurably [to] improve the lives of poor and vulnerable people,' (Rockefeller Foundation, 2010, p. 3). 'Resilience' is defined and explained in Section 4.2 below. The network operates across 4 countries to build the resilience of city systems.

In Gorakhpur, the project is implemented by the Gorakhpur Environmental Action Group (GEAG), a local NGO, and in Indore by TARU, an Indian consultancy company. Both organisations have established a City Advisory Group comprised of representatives from different fields (including the city government, the water department, town planners, the meteorological department and local businessmen) to help steer the project and review plans. In each city, they have undertaken a vulnerability assessment and helped to consolidate a 'City Resilience Strategy'.

Based on this strategy, the two organisations are undertaking different interventions. In Gorakhpur, the focus is on building climate change resilience of the Maheva neighbourhood, an informal settlement where GEAG is working closely with the community to help alleviate the problem of water logging, water stagnation, prolonged flooding and consequent impacts on health, livelihood and infrastructure. GEAG has also undertaken a pilot project on solid waste management in another locality where they organised collection and recycling of household waste. In Indore, the main intervention analysed in this paper is the pilot project on 'Conjunctive Water Management'. This is an initiative in four neighbourhoods of the city that aims to reduce water scarcity through strategies such as water harvesting, waste management and judicious use. Increased flooding and stress on water resources are well recorded urban problems that are likely to worsen with climate change (Satterthwaite et al., 2007; Wilbanks, 2007).

Studying these two cities is important, as they are part of a handful of examples where resilience thinking is being operationalised at scale. This operationalisation involves different actors, their ways of framing problems and diverse decision making fora - an ideal milieu for a study aimed at analysing the politics of building climate-change resilience. Finally, the governance structures and demographics of these cities are representative of a large number of small and medium sized urban centres in India and across many parts of the developing world, therefore results derived from research within these cities are likely to be valid across contexts.

\section{Research methods}

Data were collected using four qualitative methods. Semi-structured interviews were administered to respondents at all levels of governance of the ACCCRN project, including local (those in the informal settlement where the project was being implemented), city (the local NGOs charged with steering the project and the City Advisory Group), national (intermediary organisations between the international donor and the city partners) and 
international (the donor). Focus groups were also employed with volunteers and user groups. These were analysed both for content and observed interactions between individuals in order to inform understanding of relationships and power dynamics between various actors in the policy process. A documentary analysis covered project documents to gain essential information on the ACCCRN project and as a source of basic facts, figures and other data. This analysis was cross referenced against data collected through the other methods to compare the versions of reality that they present.

Through immersion in the spaces and processes associated with the resilience initiative for over a year, participant observation allowed insight into the nature of relationships between stakeholders in the policy process. Field notes helped supplement the other data collection methods, helping to assess the influence of social and cultural norms on policy making, an insight that other more 'direct' methods did not provide.

Exponential discriminatory snowball sampling was employed for interviews, focus groups and document analysis. This sampling process starts with a small, core set of data sources and uses these to uncover new sources, rejecting those that are not centrally aligned to the research design (Denzin et al., 2005). Data analysis was undertaken through the use of inductive approaches and manual coding techniques.

\section{Analytical and theoretical framework}

\subsection{Analytical framework: actors and networks, spaces, narratives and discourses}

This paper explores the manner in which resilience thinking interacts with policy process contexts. It employs an analytical framework that understands these contexts as the interaction between actors and networks, policy making spaces, and narratives and discourses.

The actor-oriented approach is a common approach to understanding policy processes and examines the role that actors and networks play in policy making. Keeley and Scoones (1999), p. 20 contend that the act of establishing networks is an act of establishing knowledge, arguing that '...scientific facts are only as strong as the networks that uphold them. If key individuals or institutions withdraw their support from the network, then the power of the facts weakens'. Epistemic communities have also been seen to play an important role in policy processes. These are networks of '...professionals with recognised expertise and competence in a particular domain and an authoritative claim to policyrelevant knowledge within that domain or issue area,' (Haas, 1992, p. 3). They have shared sets of beliefs, shared notions of validity and shared sets of practices to achieve a common set of goals.

The actor-oriented approach to policy processes also highlights the role of policy entrepreneurs and champions. These individuals bring ideas and issues to the policy environment, initiating institutional and policy change by leveraging '...their positions and resources to achieve desired outcomes' (Carmin and Anguelovski, 2012, p. 20). In doing so, such individuals may highlight and push for one kind of problem definition over another (Roberts and King, 1991) as well as drawing on their own personal resources of expertise, persistence and skill (Groenewegen and Steen, 2008). 
A number of theorists have placed emphasis on the spaces in which policy processes play out. Gaventa (2005) distinguishes between three types of space: closed spaces are policy making arenas that are tightly controlled by a particular group of powerful actors who make decisions without wider participation from diverse constituencies. Invited spaces are those where wider participation is solicited but the boundaries of consultation are defined by the inviting actor or institution. Claimed spaces are those' 'claimed by less powerful actors from or against the power holders, or created more autonomously by them,' (Gaventa, 2005, p. 7).

Different types of power operate within these spaces, including visible power (where one party has a discernible influence over another in decision making), hidden power (where powerful policy actors emerge influential through agenda setting), and invisible power (where influence is exerted but resembles Gramscian notions of cultural hegemony) (Lukes, 1974; Veneklasen and Miller, 2007; Gaventa, 2005). The exercise of power within policy spaces determines how different policy actors participate within policy processes.

Participation of different actors in policy spaces and decision making has been widely studied (Arnstein, 1969; Tufte and Mefalopulos, 2009; Cornwall, 2002; White, 1996; Mohan, 2001). The most widely cited typology of understanding participation in policy spaces is (Arnstein, 1969) 'Ladder of Citizen Participation' that divides participation into three broad categories, with a spectrum from 'non participation', where policy spaces are structured to exclude a diversity of voices, through 'tokenism', where participation is seen in purely 'functional' terms to enhance the efficiency or sustainability of an initiative (Cornwall, 2002), to 'citizen power' as a vision of participation that is empowering and transformational.

Finally, the analytical framework employs discourse analysis to understand the policy process. While the first generation of policy making models carries a more positivist, functional and technocratic view of knowledge (Simon, 1955; Lindblom, 1979), a later set of approaches actively problematises the idea of knowledge by examining it as discourses, narratives and frames, all inherently linked to power (Brock et al., 2001). Discourses are investigated as value laden ways of viewing policy problems and include the notion of 'framing' that addresses the ways in which seemingly value neutral issues are purposefully but implicitly projected in a particular way within policy processes to achieve particular ends (ibid). As such, knowledge for policy is produced discursively such that 'it both reflects and shapes particular institutional and political practices and ways of describing the world. Discourses frame the way in which problems are thought about, linking up different issues, often in highly programmatic, narrative cause and effect form' (Keeley and Scoones, 2003, p. 6). Crucially, some discourses may operate in direct opposition to other discourses in policy contexts (Howarth, 2005).

\subsection{Theoretical framework: resilience, adaptation and the urban imperative}

This research employs an understanding of resilience that stems from the domain of 'Socioecological Systems' (SES). Resilience is understood to be the capacity of a system to 'absorb disturbance and re-organise while undergoing change so as to still retain essentially the same function, structure, identity and feedbacks,' (Folke, 2006, p. 259). A recent review of 
the resilience literature (that subsumes the Rockefeller Foundation's conceptualisation of resilience but also draws on a wider base of literature) distilled ten key characteristics of resilience pertinent to climate change and disaster contexts, including: high diversity; effective governance and institutions; the ability to work with uncertainty and change; community involvement and the appropriation of local knowledge; preparedness and planning for disturbances; high social and economic equity; robust social values and structures, acknowledging non equilibrium dynamics, continual and effective learning and the adoption of a cross-scalar perspective (Bahadur et al., 2013).

Adaptation and disaster risk reduction (DRR) are concepts that have also been employed in designing policy responses to climate change but retain a distinction from resilience. Adaptation is rooted in engagement with specific and expected stresses; and disaster risk reduction tends to work with shorter time horizons and emphasises 'present risks' (Janssen and Ostrom, 2008; Mitchell and Van Aalst, 2008) This is in contrast to the 'future orientation' within SES resilience thinking that, through its emphasis on non-linear system dynamics, underlines the inevitability of surprise and uncertainty. Surprise and uncertainty can be managed through attributes such as redundancy, flexibility and continual learning in programs to deal with climate impacts (Folke, 2006; Norris et al. 2008; Gunderson and Holling, 2001; Moser, 2008).

The idea of socio-ecological resilience is inherently tied to systems thinking and complexity through the heuristic of the 'adaptive cycle' and 'Panarchy'. The adaptive cycle views systems as dynamic entities that shift between the four states of growth, conservation, collapse and renewal (Resilience Alliance, 2002). The notion of 'Panarchy' suggests that such cycles of creative destruction happen simultaneously at different spatial and time scales within a system (Gunderson and Holling, 2001). As such, systems are a sum of interconnected elements that interact with each other in multiple ways. Even though changes within complex systems may appear to be random, there is an underlying pattern to the way in which 'systems move through continually new states' (Ramalingam et al., 2008, p. 42). SES resilience thinking emphasises the indivisibility of humans and nature (Folke, 2006). Walker and Salt (2006, pp. 33-34) reflect on this point to note that,

'Resilience thinking is all about seeing the system - the social-ecological system that we're all part of - as one interlinked system...take a good look at the systems of which we are all a part and it soon becomes apparent that the biophysical system constrains and shapes people and their communities, just as people shape the bio-physical system.'

The majority of studies and funding on adaptation and resilience have been in the rural context and there remains a major gap in understanding resilience to climate change impacts in urban areas of developing countries (EU, 2012; Gasper et al., 2011; Mclntosh et al., 2008; Dodman, 2008; Dodman and Satterthwaite, 2008). However, there is a growing interest in urban resilience given that the increasingly urban locus of the global population (Chelleri, 2012) and most cities '...concentrate people and their homes, physical capital, industries and wastes...' whilst being predominantly located along exposed coasts and rivers (Dodman and Satterthwaite, 2008, p. 68, Dodman, 2008; Gasper et al., 2011). At the same time, city governments in developing countries often lack the resources and inclination to adequately engage with these impacts (Gasper et al., 2011). Processes of 
urbanisation themselves are often 'maladaptive' ${ }^{1}$, making cities more vulnerable to climate impacts as they increase exposure and fragment natural systems (Satterthwaite et al., 2007; Alberti and Marzluff, 2003).

As such, numerous researchers are now trying to answer questions such as 'what is urban climate change resilience?'; 'why is it important?; and, 'how is it built/achieved?'. Leichenko (2011, p. 164) argues that, '...urban resilience generally refers to the ability of a city or urban system to withstand a wide array of shocks and stresses,' defining resilience in urban areas 'as the ability of a city or urban system to absorb disturbance while retaining identity, structure and key processes' (ibid: 164). Alberti and Marzluff (2003) and Chelleri (2012) argue that the resilience of urban areas is a function of human activities as well as natural factors and building resilience requires the maintenance of an optimal balance between human services (e.g. housing, transportation) and ecosystem services.

Theorists have also stressed the importance of the relationship between urban governments and provincial governments to achieving resilience (Foster, 2007; EU, 2012; Bulkeley and Betsill, 2013; Leck and Simon, 2013). Leichenko (2011) argues that in order to support resilience urban governments need to have attributes such as '...polycentricity, transparency and accountability, flexibility, and inclusiveness,' (ibid: 46). Others have stressed spatial diversity in the supply of urban services and diversified economic activities as important to urban resilience (Chelleri, 2012; Foster, 2007). Dodman and Satterthwaite (2008) argue that cities can deal better with future climate change impacts if urban governments meet their 'current' responsibilities for the provision of infrastructure and services.

\section{Results and discussion}

The results and discussion have been organised around the domains of the analytical framework: discourses, actors and spaces.

\subsection{Discourses and urban resilience}

Three prominent discourses associated with this urban resilience initiative are examined here in relation to their congruence and dissonance with the discourses that were already in circulation in the policy contexts of Gorakhpur and Indore.

The broader discourse around climate change and resilience that accompanied the ACCCRN initiative was largely exogenous to Gorakhpur and Indore and was comprised of a number of smaller narratives. One of these was an emphasis on problems with a 'hydrometeorological' link or those that were linked to 'climate change impacts'. This influenced specific projects at the city level, with the initiative mostly focussed on multiple pathways to tackling the problem of water logging in Gorakhpur and to the problem of water scarcity in Indore.

Another ACCCRN narrative reflected resilience theory's focus on preparing for and engaging with surprises and uncertainty (Folke, 2006; Norris et al., 2008). Tyler and Moench (2012) argue that resilience helps address some of the weaknesses of a 'predict and provide' approach to climate change adaptation as it helps deal with climate change

\footnotetext{
1 “'Action or investment that enhances vulnerability to climate change impacts rather than reducing them.’'(UKCIP 2012)
} 
even under high uncertainty. This was integrated into operational plans by using a range of climate models and scenarios to underline the changing nature of future climate and highlight uncertainty in both the magnitude and direction of change. The ACCCRN also engaged vulnerable communities in Gorakhpur in discussions around 'trends' and 'patterns' of rainfall and flooding. The implicit logic guiding much of this action was that problems of water logging would unpredictably intensify in the future, requiring preparatory actions by the local population.

A third narrative that accompanied the ACCCRN was that of systems thinking and complexity. Silva et al. (2012) argue that cities are adaptive socio-technical systems and as changes within them are systemic, examining individual elements within them is an exercise of limited value. This was embodied in the ACCCRN through emphasis on collaboration between different parts of the city governance system and between different elements of target communities. The initiative thus took a systemic and participatory view of policy making, decision taking and problem solving that was centred on the coming together of diverse policy actors from different sectors of Urban Local Bodies and citizens.

Just as Howarth (2005) argued that new discourses fundamentally operate in opposition to prevailing discourses, these narratives were dissonant with a number of those in the local policy contexts of Gorakhpur and Indore. First, the discourse emphasising hydrometeorological problems was in contrast to the prevailing discourse that emphasised a range of other problems with no ostensible link to climate change. This dissonance was illustrated in the Maheva informal settlement of Gorakhpur city, where the implementation team's focus on water logging contrasted with local communities' emphasis on illicit alcohol as a key problem that needed to be dealt with on a priority basis. The clash between discourses highlighting different sets of priorities led to problems with buy in from the intended beneficiaries of the resilience initiative. Dodman and Mitlin (2013) engage with this conundrum of dissonant priorities to suggest that the endogenous community development needs should be considered alongside climate change priorities.

Similarly, the discourse on preparing for surprises, change and uncertainty contrasted with a local policy context focussed on dealing with present contingencies. Policy actors from the city government in Gorakhpur and Indore highlighted the way in which they were overwhelmed by issues that needed immediate attention such as garbage collection, accidents, and epidemics, and therefore did not have the 'luxury' of thinking about a distant future. This clash in discourses was also rooted in material realities as these policy actors did not find it expedient to expend scarce political and financial capital now for some unforeseen benefit to them after the next election. Conversely, the diversion of resources away from problems that needed immediate redress would have tangible negative repercussions for them. This divergence led many of the ACCCRN interventions to reflect a narrower set of short-term disaster risk reduction activities that tackled more immediate problems (Barr et al., 2011).

Third, while the resilience initiative brought an emphasis on systems thinking, complexity and cross-sectoral collaboration, it clashed with a prevailing discourse of compartmentalised policy making and weak cross-sectoral collaboration. This dissonance was illustrated in the conflicts that erupted in forums for collaboration convened by the 
ACCCRN. For instance, Gorakhpur had no precedent of adopting systems thinking in policy processes and therefore members from different government agencies, departments as well as citizens approached this process with their individual inherited worldviews, knowledge systems and priorities, leading to disagreements that were managed by reducing the diversity of participants. This led to a more limited vision of systems thinking in the initiative as a smaller array of perspectives was finally included.

Examining the respective stakeholder discourses and narratives reveals key insights into policy processes of, and obstacles to, building urban resilience.

First, it was seen that 'resilience thinking' came with an emphasis on cross sectoral collaboration but the existing policy context was not amenable to this. Different departments of the local authority operated in stove pipes/compartments. Urban policy environments in developing countries such as India tend to be more compartmentalised than the rural context due to, for instance, the presence of urban 'parastatal agencies' (Mukhopadhyaya et al., 2000; Chamarajm, 2009). These agencies have a powerful remit on particular sectors (with a direct link to the 'resilience' of the city) but do not effectively come under the control of city governments, having little bureaucratic compulsion to work in tandem with other departments. This helps explain why urban contexts pose particular challenges for operationalising resilience and systems thinking.

Second, new resilience discourses brought accompanying assumptions on management and governance that urged a break with the status quo. This resonates with Carmin and Anguelovski (2012), p. 20 observation that successful adaptation in cities requires 'values and goals guiding city priorities' as well as 'adjustments in institutional frameworks'. This may be hindered by the dynamics of urban governance in India. The 74th amendment to the Indian constitution provides greater authority to Urban Local Bodies, providing State governments with a list of 'mandatory' as well as 'discretionary' powers that should be devolved to such bodies (such as Municipal Corporations) (Mukhopadhyaya et al. 1999). Most State governments have acted on the minimum necessary, retained as much power as they could, leading to a severely fractured decentralisation process (Chamaraj, 2009). Therefore, Urban Local Bodies continue to have limited agency in determining regime changes, alterations in protocols and shifts in policy/strategy that building 'resilience' requires. This is also problematic in light of Dodman and Satterthwaite's (2008), p. 69 observation that decentralisation, autonomy, flexibility and responsiveness are all '...vital in boosting the resilience of cities to disasters and climate change.' A recognition of the limited potential of city governments to undertake radical change suggests that urban resilience programs must work at multiple levels of governance that include the subnational and national levels (Silva et al., 2012; Tyler and Moench, 2012).

Third, these findings criticise a linear view of policy making within which knowledge is employed rationally to inform decision making (Simon, 1955; Lindblom, 1979). Instead it resonates with the conception of policy making processes where knowledge is produced discursively and is employed by those with competing interests' (Keeley and Scoones, 2003, p. 8). 


\subsection{Actors and urban resilience}

This section explores the nature and dynamics of the actors and networks that helped perpetuate the discourses that accompanied the climate change and resilience initiative. It examines countervailing and conflicting actors/networks in the policy setting before concluding with some insights on climate change resilience, the policy process and the urban context.

Actor networks were visible in the way that the ACCCRN initiative engaged members of the local communities. In Indore, the Pilot Project on Conjunctive Water Management recruited citizens from four neighbourhoods into 'user groups'. User groups were to assist in a range of project-related tasks including data gathering, disseminating information, raising awareness, convening meetings and implementing specific resilience-building actions. Drawing on thinking from Actor - Network Theory members of 'User Groups' can been seen as 'nodes' in an networked relationship that helped in the circulation of a discourse on resilience and were key to providing traction to this exogenous narrative amongst vulnerable communities (Latour, 1996).

Even as the ACCCRN attempted to expand and perpetuate actor-networks, it came across a countervailing force in the form of 'patron-client networks' that were already in operation in these policy settings. This is a network within which a powerful actor (patron) uses her/his influence and resources to provide benefit to a less powerful actor (client) who reciprocates by offering allegiance, and diverse kinds of support and assistance (Scott, 1972). For instance, the Pradhan (councillor) in one of the localities in Indore of the Pilot Project on Conjunctive Water Management Project had a very negative attitude towards the initiative. This was because the water user group (the ACCCRN induced 'actornetwork') in the locality and its secretary were helping reduce water insecurity for the residents by building in redundant capacity (a key tenet of urban resilience) through the installation of water harvesting systems (Tyler and Moench, 2012). This threatened the Pradhan's entrenched systems of patronage through which he exchanged tankers of water in the summer for political allegiance in local elections. The negative attitude of this critically important policy actor at the local level threatened the tenability and sustainability of the project in turn. Looked at in another way, the ability of the ACCCRN to challenge these patron-client relationships in a relatively short amount of the time reflects the transformative potential of the initiative (more in Section 5.3) (Pelling, 2011).

Second, Section 4 also explored the role of epistemic communities as groups of policy actors with shared values, beliefs, notions of validity and sets of practices (Haas, 1992). At least two different sets of epistemic communities with shared values, beliefs, notions of validity and sets of practices emerged around the ACCCRN. At the international level this comprised the Rockefeller Foundation (the donor and executive), the Institute of Social and Environmental Transition (an international research organisation that was the main technical assistance partner to the donor) and other international organisations such as international consulting firm ARUP. Another epistemic community at the city level was comprised of the local lead NGO (GEAG in Gorakhpur and TARU in Indore), local academics and experts helping understand the vulnerability of the cities and preparing a 'resilience strategy', and government officials, meteorologists, businessmen, lawyers and vulnerable 
communities who fed into consultative processes to influence the design and execution of resilience building interventions.

Contests and conflicts were present amongst these two epistemic communities. Ideally the city level epistemic community was to suggest specific resilience- building interventions that would then be reviewed by the international level group and then receive funding. However, the group of organisations at the international level largely defined the key processes to be followed and which resilience interventions within cities would receive funding. Some proposals were not accepted and funding favoured interventions that best fit the innovative notions of resilience as defined by the international epistemic community. This contest over the nature of resilience-building between the two epistemic communities was indicative of what, according to project managers in Gorakhpur, was a broader divergence of opinion between international actors and actors within the cities. In their view, the international community gave preference to resilience building interventions that were 'hard' (engineering/technical solutions) whereas the local group considered 'softer' (community mobilisation, participation, awareness) approaches to be more appropriate for Gorakhpur. The need for these 'soft' approaches, such as building awareness, institutional and policy change, public education and outreach, are being increasingly recognised as important to processes of helping cities deal with climate impacts (Satterthwaite et al., 2007). This was reflected in the mid-term evaluation report of the ACCCRN, which noted that city resilience strategies as part of the initiative '....are strongly oriented towards physical planning,' (Barr et al., 2011, p. 24).

The momentum that the discourses associated with the ACCCRN enjoyed within Gorakhpur and Indore was due to the involvement of particular individuals, champions or 'policy entrepreneurs', both formal (government officials) and informal (volunteers and community leaders). Many of those interviewed identified the Municipal Commissioner of Gorakhpur as a champion. He contributed to consultative foram convened by the ACCCRN and undertook certain policy measures to embed the resilience discourse in city governance. Informal champions, including project volunteers and community leaders in Gorakhpur, helped mediate trust between the initiative and communities. For example, a local doctor used his social standing in the Maheva settlement to introduce the project team to the local residents. Perhaps the most tangible evidence of the role of informal champions was through their ability to convene community gatherings that were then employed for 'shared learning' on resilience issues.

While the activities of policy entrepreneurs were contributing to the ACCCRN's momentum, they sometimes conflicted with the interests of existing, important policy actors in these settings. In Maheva, Gorakhpur, the locally elected representative to the city government was frequently antagonistic to the activities of volunteers and community leaders (informal policy entrepreneurs) engaged in the initiative. As part of their engagement with the ACCCRN, these local policy entrepreneurs talked about a wide range of topics ranging from sanitation to agriculture as well as the role that the city government was to play in helping solve problems related to these. This process of increasing the awareness of the residents resulted in increased demands for accountability on the locally elected representative, as well as challenging his own material interests. For example, 
ACCCRN volunteers sought to address solid waste management in Maheva through new arrangements for the collection and disposal of garbage. These arrangements threatened the existing, malfunctioning system that was allegedly a source of kickbacks for the local representative. ACCCRN's destabilisation of these coercive arrangements is another example of its transformative potential (more on ACCCRN's transformative potential in Section 5.3) (Pelling, 2011).

Understanding actor networks and their influence on discourse provides further insights about the process of building climate change resilience in the urban context. First, cities and towns are where intellectual capital is concentrated and they have established epistemic cultures evidenced, for instance, through the concentration of universities, research centres and experts (Leichenko, 2011; Cooke et al., 2002). This leads to individual and distinct interpretations of resilience (as seen in the aforementioned case of how epistemic communities had divergent conceptualisations of appropriate resilience building interventions). These divergent interpretations then jostle for dominance through contests between policy actors/networks to whom they are attached. This suggests a need to better understand the ways in which 'resilience thinking' can be diffused in urban policy contexts that have prevailing intellectual enterprises and within which key policy actors approach resilience from their own inherited epistemic standpoints.

Second, these findings also underline that processes of building resilience to climate change go beyond trying to find solutions to hydro meteorological problems and must also be processes of building consensus between policy actors. For example, the alienation of local officials could have negative impacts on the durability and efficacy of the resilience initiative. Similarly, the conflict between the epistemic community at the city level and that at the international level holds the potential to yield a vision of resilience that does not reflect the realities of its operational context.

Finally, the need to build consensus becomes even more important as the emphasis on diverse viewpoints and systems stressed by resilience thinking is leading to the participation of much greater array of policy actors than before. A range of respondents noted how never before had they seen such a diversity of people attempting to scrutinise a particular issue in these policy environments. As such, arguments presented here support the centrality of individuals and actors in adaptation. This is also reflected, for instance, in the inclusion of agents/actors as one of three components of Tyler and Moench (2012) framework for urban climate resilience.

\subsection{Policy spaces and urban resilience}

Discourses of resilience and the actors/networks that helped circulate them interacted in certain policy spaces. Most of the key ACCCRN policy spaces fell into the category of 'invited spaces', where participation of prospective beneficiaries is actively solicited and the content of discussion is regulated by those steering the policy process (Cornwall, 2002). One of the first policy spaces in Maheva, Gorakhpur that provided the ordinary citizen with an opportunity for participation in the ACCCRN was a household survey conducted by the project team to map the situation prior to starting work. Volunteers described how they had to go from door to door requesting participation, informing them about the ACCCRN 
and convincing them that their responses to the survey would yield benefit. Another example of an 'invited space' was a consultative City Advisory Committee established in each ACCCRN city. This was a body of policy actors from diverse government agencies/departments, academics/experts, businessmen and civil society representatives who were to collaboratively contribute to decision making processes, simultaneously bringing alive the vision of 'systems thinking' envisaged as part of the initiative. This space was clearly 'invited' as the NGO running the ACCCRN in each city had complete control over which policy actors would participate and who would be excluded.

Apart from these invited spaces, a few of the key decision making arenas also fell into the category of 'closed spaces'. These are spaces where those who will be impacted by the policy in question are excluded from participating (Gaventa, 2005). One example of such a space was the 'sector studies' that were prepared in the formative stages of the ACCCRN in each city. These were analyses of how climate change was impacting critical sectors that defined the resilience of the city (water, solid waste management, energy, transport etc.). This crucial element of understanding the vulnerability of the city as a step towards building its resilience was led by experts, was closed to wider participation and did not integrate the views of ordinary citizens who engage with these sectors on a daily basis (Barr et al., 2011).

Most spaces within the ACCCRN where people participated were marked by a functioning of 'hidden' power. Also known as the second face of power, this is when power is exerted through the establishment of agendas and the close definition of the scope of the discussion by powerful actors (Lukes, 1974). Drawing on the work of theorists such as Ostrom (2009) who highlight the importance of community knowledge in processes of building resilience, those running the ACCCRN convened large community meetings to map climate impacts and determine pathways of resilience. These meetings were an important policy space in the initiative, intended to generate genuine dialogue and garner local knowledge. However, they mostly had a predetermined agenda from which the project team permitted only limited deviation. Therefore, for instance, in their sharp focus on issues of water logging, those delivering the ACCCRN sometimes side-stepped factors that local communities thought were critically important to their own resilience, such as illicit liquor in the neighbourhood and the lack of government identity cards that would entitle them to welfare schemes.

'Invisible power' was also evidenced in the ACCCRN, where power resembles cultural hegemony and where compliance is secured subliminally from the less powerful actor (Veneklasen and Miller, 2007). A good example of this was the elite domination of many community meetings. The elite status of these individuals was established by their being physically seated at a different level than the rest of those gathered, by their taking the lead in answering the questions and interjecting while others were speaking, and their higher caste and education levels. In one community meeting this became so acute that the participatory exercise started to resemble an interview between the project team and one other individual. 'Invisible' power was evident not only because the space for these elites to air their views was unproblematically given to them by other members of the 
community but also because those running the meetings/exercises did not contest this domination, tacitly accepting the higher status of these individuals.

The presence of invited and closed spaces that saw the functioning of hidden and invisible power led to an overtly functional form of participation within the ACCCRN initiative, but this could potentially graduate to participation that is empowering and transformational (Arnstein, 1969; Cornwall, 2002). The resilience initiative marked the very first time that socially and economically marginalised communities such as those in the Maheva settlement had been asked to take part in any policy process that would influence their surroundings. This enhanced the pressure on representatives of the city government to be accountable locally for actions, a key component of a cities adaptive capacity (Satterthwaite et al., 2007).

The threat that the ACCCRN initiative posed to local politicians and their established systems of patronage was perhaps indicative of the transformative potential that the ACCCRN held, potentially moving from an idea of resilience as 'the maintenance of the status quo' (as commonly interpreted) towards resilience as 'transformation', with the potential for shifting the balance of political and cultural power in society (Pelling, 2011). At city level it was observed that systems thinking led to the convening of diverse urban actors who had never before interacted to think about similar problems from varied epistemic standpoints - leading to shared learning. Although this was a process fraught with problems, it was also possibly the beginning of a slow process of change in these otherwise ossified policy contexts.

These findings on the dynamics of policy spaces, the nature of power within them and the influence of this on the type of participation within the resilience initiative lead to a few key insights for urban resilience. First, community involvement has been widely understood to be vital to processes of building resilience (Manyena, 2006; Mayunga, 2007; Ostrom, 2009; Nelson et al., 2007; Dovers and Handmer, 1992; Berkes, 2007; Osbahr, 2007; Norris et al. 2008; CDRSS, 2006). Yet, seeking community involvement through established participatory methods is notoriously difficult in urban areas as the community is dynamic and heterogeneous due to high rates of in and out migration. Traditional methodologies of Participation Learning and Action often fail '... where the community is very heterogeneous' (Korf, 2002, p. 67). Apart from community cohesion, a number of individuals involved in designing and implementing participatory exercises outlined how the pattern of life and the nature of livelihoods in the urban settings frustrated many established participation strategies. Participatory methods take time and, unlike rural areas where the primary source of livelihood is farming, most of Maheva's residents were involved in some form of daily wage manual labour where attending the participatory exercise would result in a direct loss in earning. Therefore, the urban context itself poses an inherent challenge to policy processes aimed at building resilience.

Second, systems thinking and the emphasis on community involvement are enabling new spaces for urban populations to participate in policy making processes. At the same time, participation within these spaces seems to be fractured because of resilience being a novel and nebulous concept that needed definition by those with 'expertise'. This is why even though marginalised urban communities such as those in Maheva, Gorakhpur started to 
participate through community meetings, the form that resilience would take was largely predetermined by organisations with expertise that were delivering the ACCCRN. This finding resonates with findings on the transformative potential of community based adaptation that simply opening participatory spaces does not lead to deep participation (Dodman and Mitlin, 2013).

Finally, understanding 'spaces' is a crucial element of an urban resilience-building process as these are conceptual and geographical venues where actors and discourses meet. One illustration of this was the dissonance between the exogenous narrative attached to the resilience initiative that prioritised hydrometeorological issues (e.g. water logging) with one that highlighted a range of other problems (e.g. illicit liquor). This dissonance was elicited in community meetings - an important policy space within the ACCCRN.

\section{Conclusion}

This paper has demonstrated the challenges that urban contexts bring to policy processes of building resilience. These include obstacles posed by a markedly compartmentalised urban policy environment to the principle of systems thinking integral to building resilience (Walker and Salt, 2006); the proliferation of on-going intellectual enterprises in cities that distinctively shape and interpret visions of resilience; and the particular challenges posed by urban contexts to securing meaningful 'community involvement', a key tenet of resilience thinking (Bahadur et al., 2013). The paper also sheds light on the unique opportunities and challenges that resilience brings to policy environments. These include factors such as the enhanced array of actors engaged in related policy processes due to its conceptual grounding in complexity and diversity, and the establishment of new policy spaces, despite fissured participation within these.

Finally, these findings support a burgeoning number of voices that underline the critical importance of acknowledging the manner in which politics and power have a determining influence on processes of building resilience to climate change (Nelson et al., 2007; Leach, 2008; Cannon and Müller-Mahn, 2010; Kuhlicke, 2010; Béné et al., 2012; Bahadur et al., 2013). We have highlighted in particular the importance of understanding how processes of building urban resilience entail clashes between competing frames of viewing problems, jostling between policy actors/networks and dynamics of participation in conceptual/geographical policy arenas. As such, the findings extend an unique insight into the manner in which different elements of a policy environment exert influence on initiatives of building urban resilience to climate change. This paves the way towards understanding processes of designing and executing urban resilience interventions that are more effective in helping those who are battling the impacts of a changing climate in some of the world's most vulnerable urban areas.

\section{Acknowledgements}

This paper would not have been possible without the generous support of the Institute for Social and Environmental Transition. The authors would also like to thank The Rockefeller Foundation, the Gorakhpur Environmental Action Group, TARU and all those who took the time to participate in interviews and group discussions. The constructive comments of participants at the 2012 Annual Conference of the Royal Geographical Society (with 
Institute of British Geographers) and two anonymous reviewers improved the text enormously. 


\section{References}

Alberti, M., Marzluff, J., 2003. Ecological resilience in urban ecosystems: linking urban patterns to human and ecological functions. Urban Ecosystems 7, 241-265.

Arnstein, S., 1969. A ladder of citizen participation. JAIP 35 (4), 216-224.

Bahadur, A., Ibrahim, M., Tanner, T.M., 2013. Characterising resilience: unpacking the concept for tackling climate change and development. Climate and Development 5 (1), 55-65.

Barr, J., Albertyn, C., Hong, V.X.N., Kundu, A., Zaituni, F., 2011. Asian Cities Climate Change Resilience Network Mid Term Evaluation. Verulam Associates Ltd., For Rockefeller Foundation, United Kingdom.

Béné, C., Wood, R., Newsham, A., Davies, M., 2012. Resilience: New Utopia or New Tyranny? Reflection about the Potentials and Limits of the Concept of Resilience in Relation to Vulnerability Reduction Programmes. IDS Working Paper \# 405, United Kingdom.

Berkes, F., 2007. Understanding uncertainty and reducing vulnerability: lessons from resilience thinking. Natural Hazards 41 (2), 283-295.

Brock, K., Cornwall, C., Gaventa, J., 2001. Power, Knowledge and Political Spaces in the Framing of Policy. Institute of Development Studies Working Paper, Brighton.

Bulkeley, H., Betsill, M., 2013. Revisiting the urban politics of climate change. Environmental Politics 22 (1), 136-154.

Cannon, T., Müller-Mahn, D., 2010. Vulnerability, resilience and development discourses in context of climate change. Natural Hazards 55 (3), 621-635.

Carmin, J., Anguelovski, I., 2012. Urban climate adaptation in the global south: planning in an emerging policy domain. Journal of Planning Education and Research 32 (1), 18-32.

CDRSS (Committee on Disaster Research in the Social Sciences), 2006. Facing Hazards and Disasters. National Research Council, Washington, DC.

Chamaraj, K., 2009. Parastatals and task forces: the new decision-makers. Retrieved from http://www.indiatogether.org/2009/ feb/gov-parastate.htm on 23rd March 2013.

Chelleri, L., 2012. From the resilient city to urban resilience. A review essay on understanding and integrating the resilience perspective for urban systems. Documents d'Anàlisi Geogràfica 58, 287-306.

Cooke, P., Davies, C., Wilson, R., 2002. Innovation advantages of cities: from knowledge to equity in five basic steps. European Planning Studies 10 (2), 233-250.

Cornwall, A., 2002. Unpacking 'Participation': models, meanings and practices. Community Development Journal 43 (3), 269- 283.

Datta, P., 2006. Urbanisation in India. Indian Statistical Institute, India. 
Denzin, N., Licoln, Y.S., 2005. The Sage Handbook of Qualitative Research. Sage, United Kingdom.

Dodman, D., 2008. Building resilience: how the urban poor can drive climate adaptation. IIED Opinion November.

Dodman, D., Satterthwaite, D., 2008. Institutional capacity, climate change adaptation and the urban poor. IDS Bulletin 39 (4), 67-74.

Dodman, D., Mitlin, D., 2013. Challenges for community-based adaptation: discovering the potential for transformation. Journal of International Development 25, 640-659.

Dovers, S.R., Handmer, J.W., 1992. Uncertainty, Sustainability and Change. Global Environmental Change 2 (4), 262-276.

EU, 2012. Urban climate resilience. Retrieved from http://www.eea.europa.eu/publications/urban-adaptation-to-climatechange2 on 1st December 2012.

Folke, C., 2006. Resilience: the emergence of a perspective for social-ecological systems analyses. Global Environmental Change 16, 253-267.

Foster, K., 2007. Snapping back: what makes regions resilient. National Civic Review 96 (3), 27-29.

Gasper, R., Blohm, R., Ruth, Mathias, 2011. Social and economic impacts of climate change on the urban environment. Current Opinion of Environmental Sustainability 3, 150-157.

Gaventa, J., 2005. Reflections on the uses of the 'power cube' approach for analyzing the spaces, places and dynamics of civil society participation and engagement. CFP evaluation series 2003-2006. No. 4. GEAG. 2009. Vulnerability analysis. Gorakhpur Environmental Action Group.

Groenewegen, J., Steen, M., 2008. Exploring policy entrepreneurship. Discussion paper series on the coherence between institutions and technologies in infrastructures WP0801.

Gunderson, L., Holling, C.S., 2001. Panarchy: Understanding Transformations in Human and Natural Systems. Island Press, Washington D.C., USA.

Haas, P.M., 1992. 'Epistemic Communities and International Policy Coordination'. International Organization. No. 1, Knowledge, Power, and International Policy Coordination (Winter, 1992), vol. 46. The MIT Press, pp. 1-35.

Howarth, D., 2005. Discourse. Viva Books, New Delhi.

Janssen, M., Ostrom, E., 2008. Resilience, vulnerability, and adaptation: a cross-cutting theme of the International Human Dimensions Programme on Global Environmental Change. Global Environmental Change 16, 237-239.

Jha, A., 2011. Much ado about the State Action Plans on Climate Change; its business as usual for the governments. PAIRVI Occasional Paper Series, August. 
Keeley, J., Scoones, I., 1999. Understanding Environmental Policy Processes: A Review. Institute of Development Studies Working Paper No. 89, United Kingdom.

Keeley, J., Scoones, I., 2003. Understanding Environmental Policy Process. Earthscan, United Kingdom.

Korf, B., 2002. Does PRA make sense in democratic societies? IIED PLA Notes June. 65-69.

Kuhlicke, C., 2010. Resilience: a capacity and a myth: findings from an in-depth case study in disaster management research. Natural Hazards 55 (3), 671-688.

Latour, B., 1996. On actor-network theory. A few clarifications plus more than a few complications. Soziale Welt 47, 369-381. Leach, M., 2008. Re-framing Resilience. A Symposium Report. STEPS Centre STEPS Working Paper 13, United Kingdom.

Leck, H., Simon, D., 2013. Fostering Multiscalar Collaboration and Co-operation for Effective Governance of Climate Change Adaptation. Urban Studies 50 (6), 1221-1238.

Leichenko, R., 2011. Climate change and urban resilience. Current Opinion in Environmental Sustainability 3, 164-168.

Lindblom, C., 1979. Still muddling, not yet through. Public Administration Review 39, 97106.

Lukes, S., 1974. Power: A Radical View. MacMillan Press, United Kingdom.

Manyena, S.B., 2006. The concept of resilience revisited. Disasters 30 (4), 433-450.

Mayunga, J.S., 2007. Understanding and Applying the Concept of Community Disaster Resilience: A Capital-Based Approach. Draft working paper prepared for the summer academy, Megacities as Hotspots of Risk: Social Vulnerability and Resilience Building, Munich, Germany, 22-28 July 2007.

McIntosh, A., Stayner, R., Carrington, K., Rolley, F., Scott, J., Sorensen, T., 2008. Resilience in Rural Communities. Centre for Applied Research in Social Science, Australia.

Mitchell, T., Van Aalst, M. 2008. Convergence of Disaster Risk Reduction and Climate Change Adaptation. A review for DfID. Retrieved from www.preventionweb.net/files/7853_ConvergenceofDRRandCCA1.pdf on 10th September 2010.

Mohan, G., 2001. Participatory development. In: Desai, V., Potter, R. (Eds.), The Arnold Companion to Development Studies. Hodder, United Kingdom, pp. 49-54.

Moser, S., 2008. Resilience in the face of global environmental change. CARRI Research Report 2.

Mukhopadhyaya, A., Jayal, N., Meenakshisundaram, S., 2000. Decentralisation in India. UNDP Discussion Paper Series 1.

Nelson, D.R., Adger, W.N., Brown, K., 2007. Adaptation to environmental change: contributions of a resilience framework. Annual Review of Environment and Resources. 32, 395-419. 
Norris, F., Stevens, S., Pfefferbaum, B., Wyche, K., Pfefferbaum, R., 2008. Community resilience as metaphor, theory, set of capacities, and strategy for disaster readiness'. American Journal of Community Psychology 41 (1-2), 127-150.

Osbahr, H., 2007. Building Resilience: Adaptation Mechanisms and Mainstreaming for the Poor. Human Development Report Occasional Paper.

Ostrom, E., 2009. A general framework for analyzing sustainability of socio-ecological systems. Science 325 (5939), 419-422.

Pelling, M., 2011. Adaptation to Climate Change: From Resilience to Transformation. Taylor \& Francis, New York.

Ramalingam, B., Jones, H., Reba, Y., Young, J., 2008. Exploring the Science of Complexity: Ideas and Implications for Development and Humanitarian Efforts. Working Paper 285 Overseas Development Institute, United Kingdom.

Resilience Alliance, 2002. Resilience. Retrieved from www.resalliance.org/576.php on 15th March 2013.

Roberts, N.C., King, P.J., 1991. Policy entrepreneurs: their activity structure and function in the policy process. Journal of Public Administration Research and Theory 1 (2), 147175.

Rockefeller Foundation, 2010. Asian Cities Climate Change Resilience Network. Rockefeller Foundation, USA.

Satterthwaite, D., Huq, S., Pelling, M., Reid, H., Lankao, P., 2007. Adapting to Climate Change in Urban Areas. International Institute of Environment and Development, United Kingdom.

Silva, J., Kernaghan, S., et al, 2012. A systems approach to meeting the challenges of urban climate change. International Journal of Urban Sustainable Development 4 (2), 125-145.

Scott, J., 1972. Patron-client politics and political change in southeast asia. The American Political Science Review 66 (1), 91- 113.

Simon, H.A., 1955. A behavioural model of rational choice. Quarterly Journal of Economics 69, 99-118.

Tyler, S., Moench, M., 2012. A framework for urban climate resilience. Climate and Development 4 (4), 311-326, October 2012.

TARU, 2010. Phase 2: City Vulnerability Analysis Report Indore and Surat. TARU, India. Tufte, T., Mefalopulos, P., 2009. Participatory Communication. The World Bank, USA. UKCIP, 2012. Glossary. Retrieved from http://www.ukcip.org.uk/glossary/\#M on 5th August 1983. 
VeneKlasen, L., Miller, V., 2007. A New Weave of Power, People and Politics: The Action Guide for Advocacy and Citizen Participation. Practical Action Publishing, United Kingdom.

Walker, B., Salt, D., 2006. Resilient Thinking. Sustaining Ecosystems and People in a Changing World. Island Press, USA.

White, S., 1996. Depoliticising development: the uses and abuses of participation. Development in Practice 6 (1), 6-15.

Wilbanks, T.J., Romero Lankao, P., Bao, M., Berkhout, F., Cairncross, S., Ceron, J.-P., Kapshe, M., Muir-Wood, R., Zapata-Marti, R., 2007. Industry, settlement and society. In: Parry, M.L., Canziani, O.F., Palutikof, J.P., van der Linden, P.J., Hanson, C.E. (Eds.), Climate Change 2007: Impacts, Adaptation and Vulnerability. Contribution of Working Group II to the Fourth Assessment Report of the Intergovernmental Panel on Climate Change. Cambridge University Press, Cambridge, UK, pp. 357-3903. 